\title{
Innervation of the Kidney of Aplysia by L10, the LUQ Cells, and an Identified Peripheral Motoneuron
}

\author{
J. Koester ${ }^{1,2,4}$ and A. Alevizos ${ }^{1,3,4}$ \\ ${ }^{1}$ Center for Neurobiology and Behavior, ${ }^{2}$ Department of Psychiatry, and ${ }^{3}$ Department of Physiology and Cellular \\ Biophysics, College of Physicians and Surgeons, Columbia University, New York, New York 10032, and ${ }^{4}$ The New York \\ State Psychiatric Institute, New York, New York 10032
}

The purpose of this study was to begin to describe the neural circuit within the abdominal ganglion that modulates renal functioning in Aplysia. We found that the previously described cholinergic neuron L10 and peptidergic left upper quadrant (LUQ) neurons have important roles in the control of the kidney. Cell L10 and a subset of the LUQ cells branch extensively within the kidney and send major processes to the renal pore, a sphincter that controls the efflux of urine. The renal pore has circular (closer) and radial (opener) muscle fibers that act as antagonists. Embedded within the wall of the renal pore is a newly identified peripheral neuron, RPO, which is a renal pore opener motoneuron. L10 activity causes opening of the renal pore by directly exciting pore opener muscle, inhibiting closer muscle, and exciting RPO. When RPO is active, it generates synchronous, discrete twitches in the opener muscle fibers. The action potentials recorded in RPO exhibit pronounced broadening at physiological rates of firing. LUQ cells that project to the renal pore cause it to close, and they antagonize the opening generated by an L10 burst. The pore closing caused by the LUQ cells is mediated in part by heterosynaptic inhibition of the L10 to RPO excitatory connection. The previously described central inhibitory connections from L10 to the LUQ cells ensure that these 2 classes of antagonists fire out of phase with each other. Our data, along with those from earlier studies demonstrating that $L 10$ plays an important role in controlling the circulatory system, suggest that $L 10$ and the LUQ cells modulate various aspects of renal function in Aplysia, including filtration and micturition.

Aplysia has been used extensively as a model system for the study of the neural control of circulation. Little is known, however, concerning the neural control of the kidney, which in Aplysia is closely linked to the circulatory system (Fig. 1). The goal of this study was to begin to describe the basic neural circuitry within the abdominal ganglion that coordinates renal and circulatory function.

Aplysia has a semiopen circulatory system (Fig. 1). The heart

\footnotetext{
Received Nov. 25, 1988; revised Apr. 28, 1989; accepted May 5, 1989.

We thank Drs. S. L. Hooper and K. R. Weiss for critically reading an earlier draft of this paper, and Dr. R. H. Kramer for showing us his unpublished data on L10. This work was supported by NIH grants NS19328 and GM32099 and the Hellenic University Club of New York.

Correspondence should be addressed to Dr. John Koester, Center for Neurobiology and Behavior, The New York State Psychiatric Institute, 722 West 168th Street, New York, NY 10032.

Copyright (c) 1989 Society for Neuroscience $0270-6474 / 89 / 114078-11 \$ 02.00 / 0$
}

pumps blood via the arteries throughout the body. Fine arterioles terminate in open vascular spaces that bathe the cells of the various tissues. The blood then accumulates in the haemocoele, from which it flows by 2 parallel collecting sinuses into the gill and the kidney before returning to the heart. Morphological evidence suggests that renal excretion in Aplysia begins with the formation of an ultrafiltrate of blood that passes across the wall of the crista aortae into the pericardium (Andrews, 1988). This pericardial fluid flows through the cilia-lined renal-pericardial pore into the lumen of the kidney. Within the kidney, the ultrafiltrate is further elaborated into urine by secretion and reabsorption across the epithelial sheet of the kidney. Urine leaves the kidney via the muscular, cilia-lined renal pore, which is located near the posterior base of the gill (Eales, 1921).

What little is known about the innervation of the kidney in Aplysia suggests that the abdominal ganglion plays a central role in its neural control. Two cells in the ganglion have motor functions that affect the kidney: firing cell $\mathrm{LC}_{\mathrm{K}}$ contracts muscle within the kidney, and cell $\mathrm{LC}_{\mathrm{P}}$, by contracting the pericardium, is likely to influence flow of the ultrafiltrate (Koester and Kandel, 1977). The peptidergic cell R11 sends an axon to the kidney via the branchial nerve (Rittenhouse and Price, 1986), but its physiological actions are unknown. The pericardial nerve, 1 of the 4 major peripheral nerves of the abdominal ganglion, provides the major source of innervation of the kidney.

Two well-studied cell types in the abdominal ganglion-cell L10 and the 5 left upper quadrant (LUQ) cells-send axons out the pericardial nerve (Frazier et al., 1967; Winlow and Kandel,

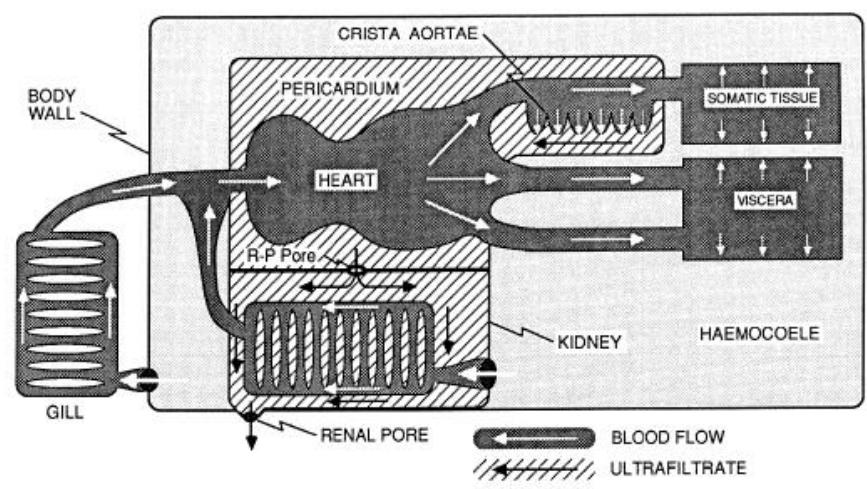

Figure 1. Schematic diagram of renal and circulatory system of Aplysia. $R P$, renal-pericardial. After the descriptions by Eales (1921) and Andrews (1988). 


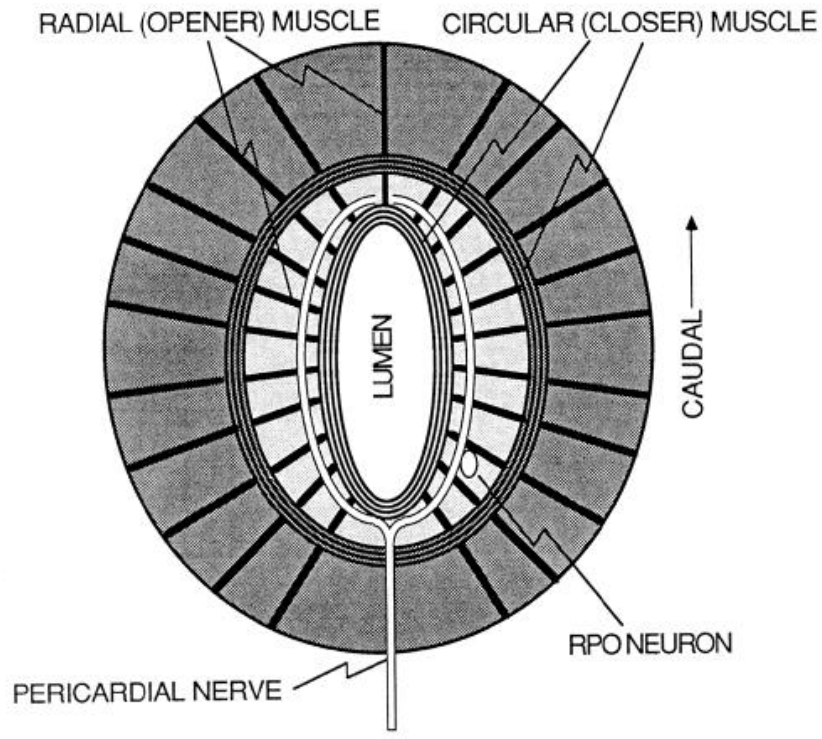

Figure 2. Schematic diagram of the neuromuscular system of the renal pore (ventral side up). The wall of the pore is a vascular space that is lined medially and laterally with circular bands of closer muscle fibers. Radiating out from the center of the pore are the bands of opener muscle fibers, which attach to the dorsal body wall of the floor of the mantle cavity. The pericardial nerve enters the pore at its rostral edge, after which it branches before continuing caudal. The bipolar soma of the peripheral RPO neuron is located about one-quarter of the way back along the right branch. It sends axons around the circumference of the pore, through the pericardial nerve.

1976). The physiological function of cell L10 is of particular interest because this neuron has been used for numerous cellular studies of the physiology and pharmacology of cholinergic transmission, electrical transmission, axonal transport, various forms of synaptic plasticity, multicomponent chemical synaptic transmission, pacemaker entrainment and modulation, and patterns of circuit organization (reviewed by Kandel, 1976; Pinsker, 1977; McCaman and Ono, 1982; Segal and Koester, 1982). We have found recently (Alevizos et al., 1987) that L10 synthesizes the neuropeptide myomodulin (Cropper et al., 1987) in addition to acetylcholine (ACh). Transient increases in heart rate are produced by endogenously generated bursts of activity in neuron $\mathrm{L} 10$ that are relayed by heart excitor neuron $\mathrm{RB}_{\mathrm{HE}}$ (Koester et al., 1974; Kandel, 1976). Furgal and Brownell (1987) have shown that L10 activity is enhanced when the flow of hemolymph or oxygen tension within the ganglion is reduced. The LUQ cells, L2-L6, which are strongly inhibited by L10 (Kandel et al., 1967), have been used extensively for studies of the mechanisms of endogenous bursting (Kramer and Zucker, 1985). The transmitter types of the LUQ cells are unknown, although neuron L5 has been shown to express a gene that encodes a molecule with the characteristics of a neuropeptide (Shyamala et al., 1986). In addition, 3 of the LUQ cells are immunoreactive for a putative neuropeptide encoded in a gene that was originally found to be expressed in cell L11 (Taussig et al., 1985). Both L10 and the LUQ cells are strongly modulated by neuropeptides released by the bag cells during egg-laying (Mayeri et al., 1979a, b).

In spite of the detailed information concerning the cellular properties of L10 and the LUQ cells, their physiological roles, except for the effect of L10 on heart rate, remained unknown. In this paper we demonstrate that L10 and a subset of the LUQ cells, along with the newly identified peripheral RPO motoneuron, modulate renal excretion by controlling the opening of the renal pore. Morphological evidence suggests that L10 and the LUQ cells innervate other regions of the kidney as well. Some of these results have been reported previously in abbreviated form (Koester et al., 1987; Koester, 1988).

\section{Materials and Methods}

Animals. Specimens of Aplysia californica weighing 3-1000 gm were supplied by Marinus (Long Beach, CA), Sea Life Supply (Sand City, $\mathrm{CA})$, and the Howard Hughes Medical Institute Marine Resources Facility at the Woods Hole Oceanographic Institute (Woods Hole, MA). Most experiments were done on specimens weighing 80-120 gm, with 2 exceptions: small $(3-5 \mathrm{gm})$ animals were used when the peripheral distributions of axons were mapped in dye-filling experiments, and large $(600-1000 \mathrm{gm})$ animals were used when recording from the peripheral motoneuron (RPO). Animals were maintained in an aquarium containing artificial seawater (ASW) (Instant Ocean) at $15^{\circ} \mathrm{C}$ until used. The results described below were obtained from 75 preparations.

Electrophysiology. After anesthetizing the animal by injecting isotonic $\mathrm{MgCl}_{2}$ (25\% of body weight), the abdominal ganglion and the kidney, connected by the pericardial nerve, were dissected from the animal. This tissue was placed in a recording chamber filled with ASW. The kidney was dissected down to just its dorsal and rostral walls, which were pinned out flat on the clear silicon elastomer coating (Sylgard; Dow Corning) on the bottom of the chamber. Single- or double-barreled glass microelectrodes (2-5 M $\Omega$ ) filled with $2 \mathrm{M}$ potassium acetate were used to record membrane potential and, using a bridge circuit, to pass current into nerve cells. Neurons were impaled by tapping the electrode through the connective tissue sheath of the ganglion. Single-barreled electrodes (10-15 M $\Omega$ ) were used to record intracellularly from muscle fibers in the renal pore. Before recording from the RPO peripheral motoneuron (Fig. 2), most of the renal pore was dissected away from the pericardial nerve. The sheath surrounding the RPO cell then was softened by bathing the tissue in ASW containing 1\% protease (Type IX, Sigma) for 10 $\min$ at $34^{\circ} \mathrm{C}$.

Two test solutions were applied to the ganglion to test whether neurons in the ganglion project directly to peripheral tissues. In both cases, the ganglion was isolated from the rest of the recording chamber by placing it in a $1 \mathrm{ml}$ well that was sealed around the ganglion with petroleum grease: (1) A saline solution high in divalent cations was used in some experiments to raise spike threshold, thereby blocking most polysynaptic pathways. This solution, which contained 2.5 times the normal concentrations of $\mathrm{Mg}^{2+}$ and $\mathrm{Ca}^{2+}$ (normally 55 and $10 \mathrm{mM}$, respectively), was prepared by mixing isotonic $(340 \mathrm{~mm}) \mathrm{CaCl}_{2}$ and isotonic $(340 \mathrm{~mm})$ $\mathrm{MgCl}_{2}$ with ASW. (2) A saline solution in which $\mathrm{Ca}^{2+}$ was replaced with equimolar $\mathrm{Co}^{2+}$ was used to block chemical transmission.

Because of the low magnification $(40 \times)$ of the dissecting microscope used in these experiments, muscle fibers in the region of the renal pore were impaled blind. Although the regions where radial (opener) and circular (closer) fibers lie can be identified quite easily with these optics, we iontophoretically filled a few of the fibers with the fluorescent dye 5,6-carboxyfluorescein (Kodak; Rao et al., 1986) to confirm that they were indeed muscle fibers and that they had the predicted orientation, i.e., circular or radial.

Two methods were used for extracellular recording. For focal recording, a fire-polished, ASW-filled glass macroelectrode, with a $50 \mu \mathrm{m}$ tip diameter, was used to record axon spikes by pressing the tip against the pericardial pore. For global recording, the region of the kidney wall that includes the termination of the pericardial nerve at the renal pore (Fig. 2) was centered over a small (8-mm-diameter) pedestal of vaselinecoated Sylgard that protruded $2 \mathrm{~mm}$ above the floor of the recording chamber. In the center of the pedestal was an electrode consisting of a small, plastic vertical tube ( $1.5 \mathrm{~mm}$ diameter) filled with ASW. The top end of the tube, which was open to the bath, was flush with the top surface of the pedestal. Sealed into the bottom end of this tube was an insulated $\mathrm{Ag}-\mathrm{AgCl}$ wire that was used to lead off the electrical signals from the pore to a preamplifier. After centering the renal pore over the open end of the tube, the tissue was insulated from the bath by lightly stretching a thin latex membrane over the pedestal. By comparing the signals between the indifferent electrode in the bath and the electrode 
embedded under the pore, it was possible to record the compound electrical activity of the neuromuscular system that controls pore opening.

The effects of identified cells on pore opening were recorded using a chamber that had a photocell embedded in the Sylgard coating on its bottom. The Sylgard floor was covered with a piece of aluminum foil, which had a $1 \mathrm{~mm}$ hole centered over the photocell. The dorsal wall of the kidney was then pinned to the bottom of the chamber, with the renal pore positioned over the hole in the aluminum foil. The pore was illuminated from above with a fiberoptic source. When the pore opened, the light falling on the photocell increased. The aluminum foil served to cut down on stray light transmitted through the partially translucent kidney wall surrounding the pore.

The ASW in the recording chamber was maintained at $16 \pm 1^{\circ} \mathrm{C}$ by a Peltier cooling plate. All data were tape-recorded and played back on a Gould 440 chart recorder (full-scale cut-off frequency, $40 \mathrm{~Hz}$ ) or on a storage oscilloscope for photographing.

Light microscopy. To label the fields of innervation of the kidney by L10 and the LUQ cells for whole-mount viewing, the kidney was dissected down to just the dorsal and rostral walls, attached by the pericardial nerve to the abdominal ganglion. 5,6-Carboxyfluorescein was iontophoresed (2-3 nA for 5-12 hr) into the cell body of a particular neuron in the abdominal ganglion. The ASW bathing the ganglion contained $5 \mathrm{~mm}$ probenecid (Sigma) to reduce transport of the dye out of the cell (DiVirgilio et al., 1988). After allowing the dye to diffuse throughout the cell for $24-48 \mathrm{hr}$ at $4^{\circ} \mathrm{C}$, the preparation was photographed at several depths of focus in whole mount with a microscope equipped for epifluorescence viewing. The peripheral projections of the cell were traced from the negatives. The peripheral RPO neuron was labeled in a similar fashion, except that the filling time was $30 \mathrm{~min}$ and the dye was allowed to diffuse for only an hour after the injection.

For immunostaining, we used a modified version of the technique developed by Longley and Longley (1986) for staining whole mounts (see Alevizos et al., 1989, for details). The glyoxylic acid method of staining for biogenic amines in Aplysia (Hawkins, 1986) was used to confirm immunocytochemical indications that serotonin is present in the crista aortae.

Pharmacology. Hexamethonium bromide and $\mathrm{ACh}$ were obtained from Sigma. In experiments in which these substances were applied, the renal pore was perfused continuously with ASW. The effects of ACh on renal pore opening were measured by injecting a small bolus of $\mathrm{ACh}$ in ASW into the perfusion line. The effects of hexamethonium on pore opening were measured by switching the perfusate from ASW to ASW plus hexamethonium.

\section{Results}

\section{Innervation of the renal system}

Fine dissection confirmed the report by Kandel (1979) that the major source of innervation of the kidney is via the pericardial nerve. The nerve enters the kidney at the renal pericardial pore, at which point it divides in two. One branch goes to the auricle of the heart (Mayeri et al., 1974) and the second one ramifies within the kidney. The main trunk of this second branch extends along the dorsal wall of the kidney to its caudal edge, where it ends at the renal pore.

The renal pore is elliptical, with axes of approximately $1 \times$ $1.5 \mathrm{~mm}$ in a $100 \mathrm{gm}$ animal. In its functional role as a sphincter, it is controlled by 2 types of muscle: circular muscle fibers, which line the inner and outer walls of the pore, mediate closing of the pore; radial fibers, which radiate out from the wall of the pore and attach to the dorsal body wall, mediate pore opening (Fig. 2).

The branch of the pericardial nerve innervating the renal pore forks after entering the rostral edge of the pore (Fig. 2). The 2 secondary branches of the nerve continue back along the pore wall to its caudal edge. About one-fourth of the way back on the right-hand branch is found the elliptical soma of a single peripheral neuron, with axes of about $80 \times 120 \mu \mathrm{m}$ (in a 600 gm animal). Injecting the cell with 5,6-carboxyfluorescein re-
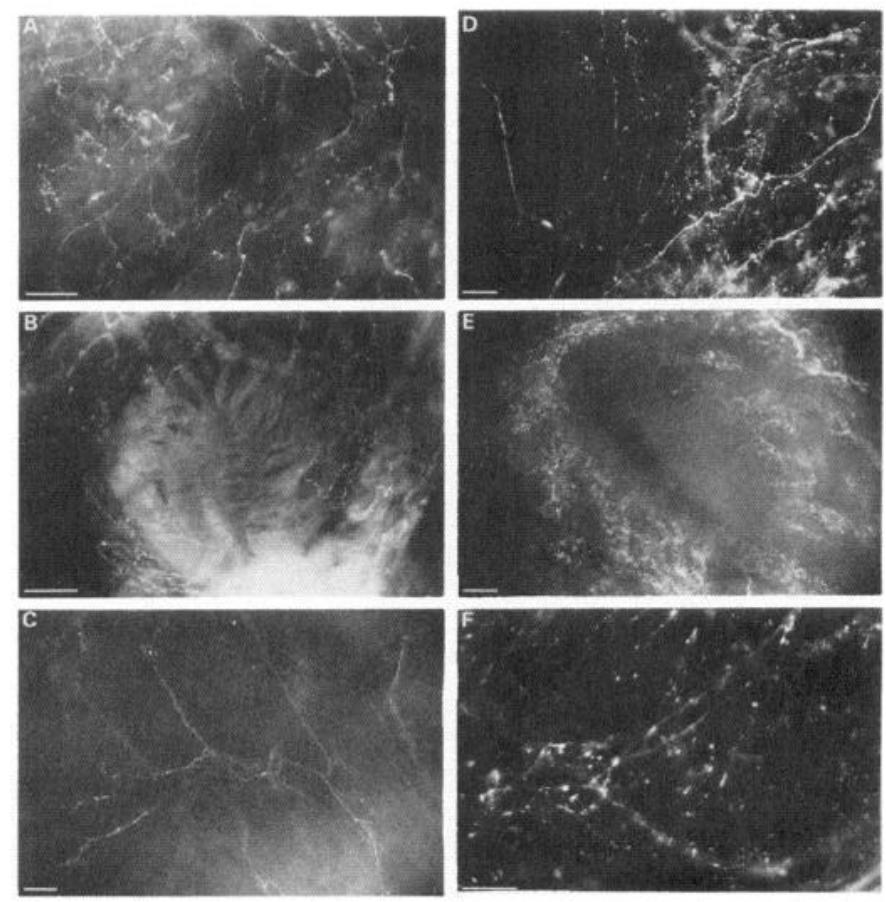

Figure 3. The renal system is richly innervated by axon terminals that are immunoreactive for 5-HT and FMRFamide. $A$, Ventral surface of dorsal kidney wall labeled with serotonin antibody. $B$, Ventral surface of renal pore labeled with 5-HT antibody. $C$, Crista aortae labeled with 5-HT antibody. Similar results were obtained using the glyoxylic acid method of staining for serotonin. $D$, Ventral surface of dorsal kidney wall labeled with FMRFamide antibody. $E$, Ventral surface of renal pore labeled with FMRFamide antibody. $F$, Renal-pericardial pore labeled with FMRFamide antibody. Scale bars: $250 \mu \mathrm{m}, A-E ; 160 \mu \mathrm{m}$, $F$. The results shown here are representative of those obtained in 5 preparations for each condition.

vealed that it is bipolar. The combined length of its 2 axons, running within the 2 branches of the pericardial nerve, circumscribes the wall of the pore. Each major process sends off several minor branches along its entire length. Because the nerve had to be finely trimmed in order to impale the cell, we could not follow these secondary processes to their terminations, but indirect evidence presented below suggests that they terminate on opener muscle. We have named this peripheral neuron the renal pore opener (RPO) cell, for reasons described below. Further dissection revealed no additional peripheral neurons within the renal pore, or in other regions of the kidney. However, a more systematic approach based on serial sectioning of the entire kidney will be required to rule out definitely such a possibility.

In order to obtain a general picture of the extent of innervation of the renal system, we used 2 histological approaches to visualize in whole mount 2 transmitters that are widely distributed in Aplysia: 5-HT and FMRFamide (Lehman et al., 1984). The crista aortae was found both by the glyoxylic acid method and by immunocytochemistry to be richly innervated by serotonergic nerves (Fig. 3C). FMRFamide and 5-HT immunoreactivity were found in fine neuronal processes and varicosities throughout the kidney, including the dorsal wall of the kidney and the renal pore (Fig. 3, $A, B, D, E$ ). We did not attempt to use labels with different fluorophores to address the issue of whether the 2 immunoreactive substances are colocalized. The wall of the renal-pericardial pore also contains terminal pro- 


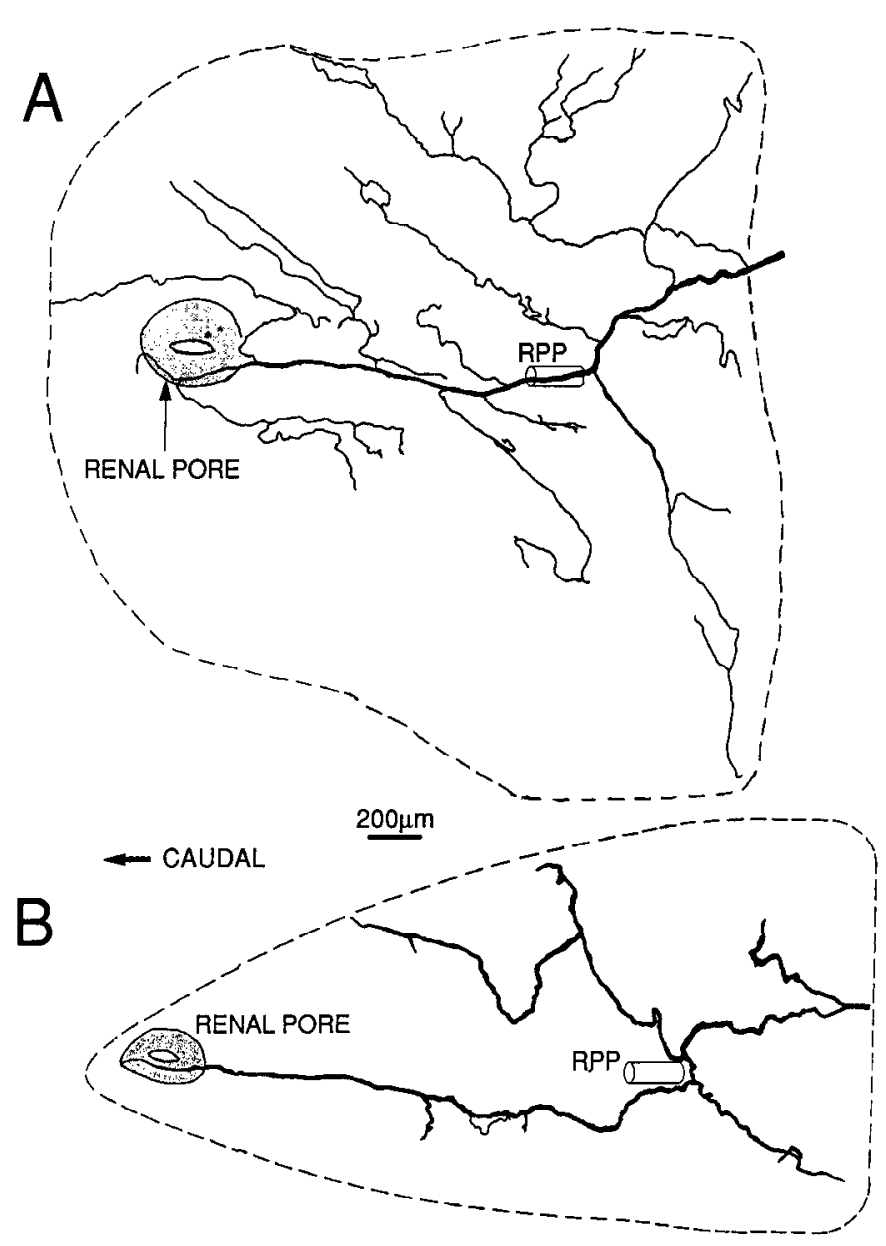

Figure 4. Innervation of the kidney by $\mathrm{L} 10$ and the LUQ cells. $A$, Tracing of a fluoresence micrograph of the axon field of a 5,6-carboxyfluorescein-injected LUQ cell on the rostral and dorsal surfaces of the kidney. $B$, Tracing of a fluoresence micrograph of the axon field of a 5,6-carboxyfluorescein-injected L10 cell ramifying over the rostral and dorsal surfaces of the kidney. Animal weight was $3 \mathrm{gm}$ in both $A$ and $B$.

cesses that are immunoreactive for FMRFamide (Fig. $3 F$ ). In control experiments, we tested the antibodies for specificity by applying them to the abdominal ganglion. Both the 5-HT and the FMRFamide antibodies bound selectively to the same groups of cells that had been labeled in other studies by various investigators (Brown et al., 1985; Kistler et al., 1985; Longley and Longley, 1986; Ono and McCaman, 1984).

The LUQ cells seemed to be likely sources for at least some of the FMRFamide immunoreactivity found in the kidney. They previously had been shown to express a gene that encodes a neuropeptide possessing significant structural homology to the carboxy terminus of FMRFamide (Shyamala et al., 1986) and to be immunoreactive to antibodies for FMRFamide (Brown et al., 1985). This immunoreactivity is likely to result from the general nonspecificity of antibodies to FMRFamide (Verhaert et al., 1985): there is no direct evidence that the LUQ cells synthesize FMRFamide. To test whether the LUQ cells innervate the kidney, we filled the cell bodies of randomly selected LUQ cells with 5,6-carboxyfluorescein and followed their axons out the pericardial nerve toward the kidney. In each of 4 preparations, the filled processes of the LUQ cell ramified extensively over the dorsal and rostral surfaces of the kidney. In 3 out of

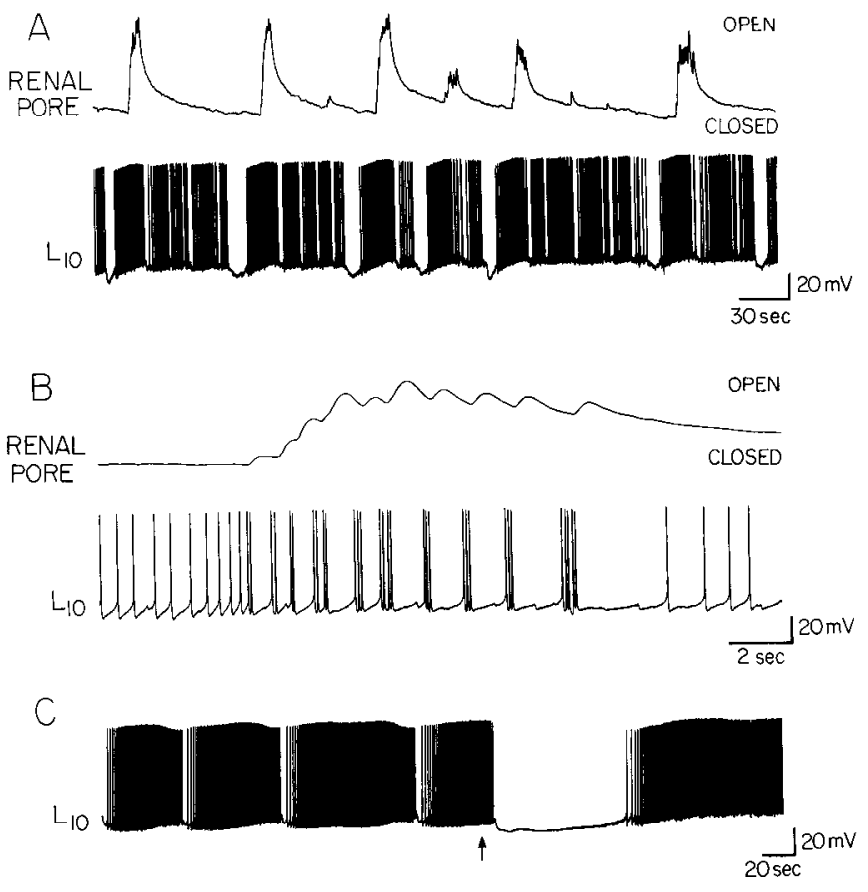

Figure 5. L10 activity is correlated with opening of the renal pore. $A$, Spontaneous bursts in L10 are correlated with spontaneous transient openings of the renal pore. $B$, No twitches occur during the initial phase of the burst, when L10 fires at a relatively low frequency. All of the twitches occur relatively late in the L10 burst, when they are correlated with brief minibursts of 2-5 spikes, during which the instantaneous spike frequency reaches its highest values. Note that the later spikes within each miniburst rise abruptly from the baseline, suggesting that they are triggered antidromically. $C$, Light touch of the pore evokes a strong closing reflex (visual observation), correlated with strong inhibition of $\mathrm{L} 10$.

the 4 specimens, a major branch of the injected LUQ cell projected all the way to the renal pore at the caudal edge of the kidney (Fig. 4A). This morphological picture was supported by combining intracellular and extracellular recordings, which showed that action potentials recorded in the cell bodies of some LUQ cells are coupled 1:1 with action potentials recorded extracellularly from sites throughout the dorsal wall of the kidney, including the renal pore (unpublished observations).

The cell body of L10 also was filled iontophoretically with 5,6-carboxyfluorescein to trace its peripheral field of innervation $(n=3)$. A single L10 axon exits the ganglion within the pericardial nerve (Gillette and Pomeranz, 1973) and extends to the renal-pericardial pore, where it enters the kidney (Fig. 4B). The axon divides at this point, sending numerous secondary branches throughout the dorsal and rostral walls of the kidney, including one that goes to the renal pore. This morphological picture was confirmed in 11 experiments by simultaneous recording of electrical activity from the soma of L 10 and from its peripheral processes. In every case an action potential in the soma of L10 was followed at short and constant latency by an action potential in the pericardial nerve where it enters the renal pore (see Fig. 9A), as well as in various others regions distributed throughout the kidney.

\section{Renal pore opening is mediated by $L 10$}

In each of 25 semi-intact preparations used in this study, the renal pore opened rhythmically, typically at about once per 
Figure 6. L10 activity causes opening of the renal pore. $A$, Hyperpolarizing L10 to block spontaneous bursting for 5 min blocks almost completely the spontaneous pore openings (mean \pm SEM of results from 5 preparations). $B$, Firing L 10 by injected current triggers pore opening. Note that the twitches are not correlated $1: 1$ with action potentials in $\mathrm{L} 10$ (this figure is representative of results obtained in 20 experiments). Similar results were obtained with the ganglion bathed in either of 2 solutions applied to the ganglion to block polysynaptic pathways: high-divalent cation saline or $\mathrm{Ca}^{2+}$-free saline containing $10 \mathrm{mM} \mathrm{Co}^{2+}$.
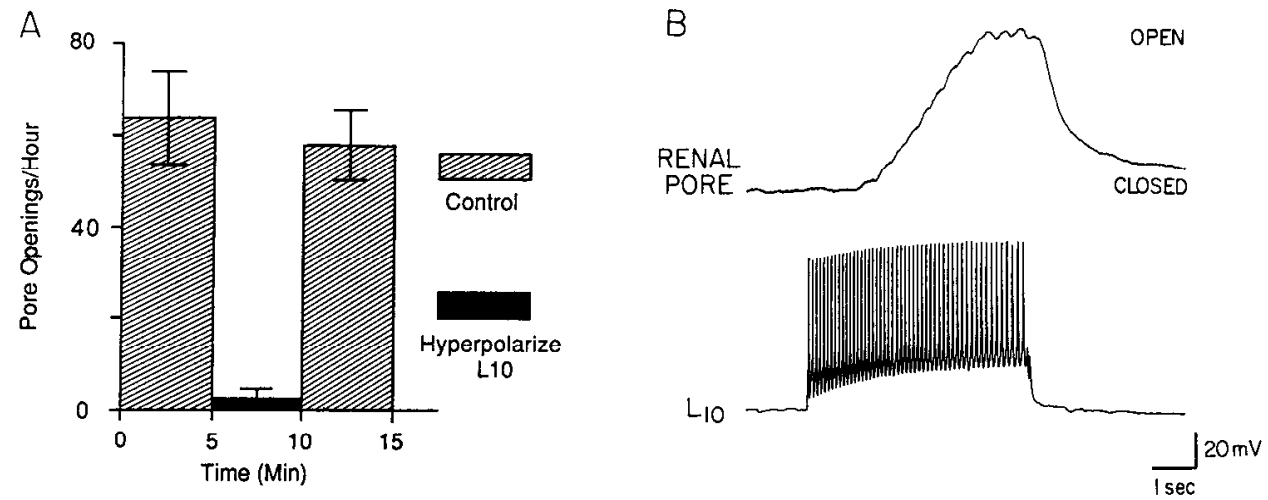

minute. This frequency corresponds roughly to the endogenous burst frequency of $\mathrm{L} 10$ recorded in a more intact preparation (Koester et al., 1974), suggesting that it might be triggered by L10 bursts. Intracellular recording from L10 showed that periodically occurring openings of the pore were indeed correlated $1: 1$ with spontaneous high-frequency bursts in L10 (Fig. $5 A$ ), in each of 25 preparations. In every case, the pore began to open in discrete twitches about half-way through each high-frequency L10 burst. When L10 bursts spontaneously, it typically fires in doublet or triplet patterns during the middle- to late phases of the burst. In the example shown, single spikes in L10 were ineffective in mediating pore opening, but L10 doublets or triplets were correlated closely with single twitches of the opener muscle (Fig. 5B). This correlation of twitches with doublet or triplet spikes was not observed in every preparation. In some cases, the discrete twitches began to occur earlier in the L10 spike train, when it was still firing regularly. But in no L10 burst did the discrete twitches ever begin until L10 had already fired $10-20$ action potentials at relatively high frequency. Although the early spikes in a train do not trigger the discrete twitches illustrated in Figure $5, A, B$, they typically produced a slow, graded contraction, which is not visible on the relatively lowgain records shown here. If $\mathrm{L} 10$ activity were causally related to renal pore opening, one might expect that $\mathrm{L} 10$ would be inhibited when the pore closes reflexively. Touching the pore does indeed trigger a vigorous reflex closing of the pore, associated with inhibition of $\mathrm{L} 10$ (Fig. $5 C$ illustrates a representative result from 5 experiments).

Several additional types of evidence suggest that the activity in L10 is directly involved in mediating opening of the renal pore: (1) As mentioned above, extracellular recording from the branch of the pericardial nerve that innervates the renal pore shows that L10's action potentials recorded at the pore follow the action potentials generated in L10's soma 1:1 (Fig. 9A). This supports the morphological evidence cited above (Fig. $4 B$ ) that L10 sends a major process to the pore. (2) Hyperpolarizing L10 for $5 \mathrm{~min}$ to keep it from bursting reduces the frequency of spontaneous renal pore openings by 30 -fold (Fig. $6 A$ ). Similar results are obtained if $\mathrm{L10}$ 's axon is cut by severing the pericardial nerve (data not shown). Under both experimental conditions, however, the pore still continues to open in a small minority of preparations. This result indicates that there is a second (ectopic) pacemaker, located outside the ganglion, that can take over the control of pore opening in the absence of spikes initiated in the L10 soma. (3) Firing L10 by current injection causes the renal pore to open in a series of discrete twitches (Fig. 6B). As is true for twitches that are correlated with spontaneous L10 activity, however, these twitches do not follow 1:1 the spikes in L10. (4) The motor effect generated by firing L10 persists with the ganglion bathed in high divalent cation solution or in $\mathrm{Ca}^{2+}-$ free, $\mathrm{Co}^{2+}$ saline to block polysynaptic pathways (data not shown). (5) Excitatory- and inhibitory-junction potentials (EJPs and IJPs) that follow L10's action potentials 1:1 are recorded from the opener and closer muscle fibers, respectively, of the renal pore (Fig. 7). (6) Perfusing the renal pore with $10^{-5} \mathrm{MACh}$, the transmitter of L10, mimics the effect of L10 on pore opening (Fig. 8A). Perfusing with $5 \times 10^{-5} \mathrm{M}$ hexamethonium, a specific blocker of the excitatory action of ACh in Aplysia (McCaman and Ono, 1982), reversibly blocks the pore opening effect of $\mathrm{L} 10$ activity (Fig. $8 B$ ). The data in Figure 7 demonstrate that $\mathrm{L} 10$ causes pore opening in part by a direct action on pore muscle. But the lack of 1:1 coupling

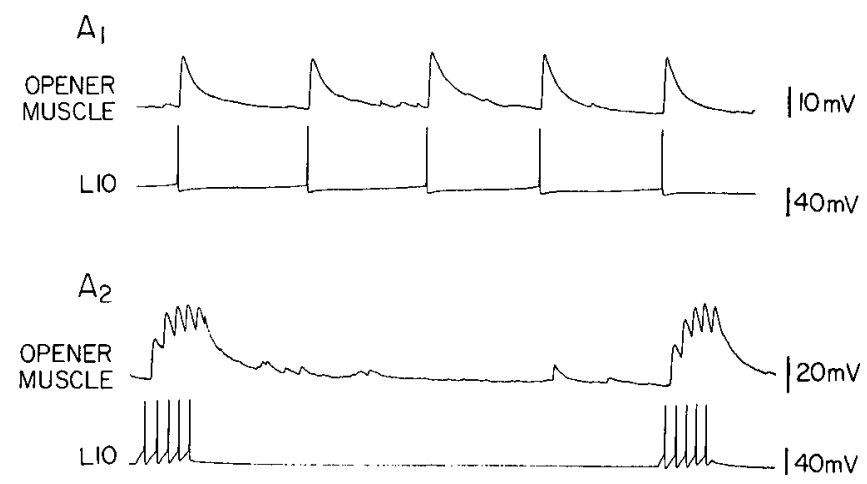

$B$

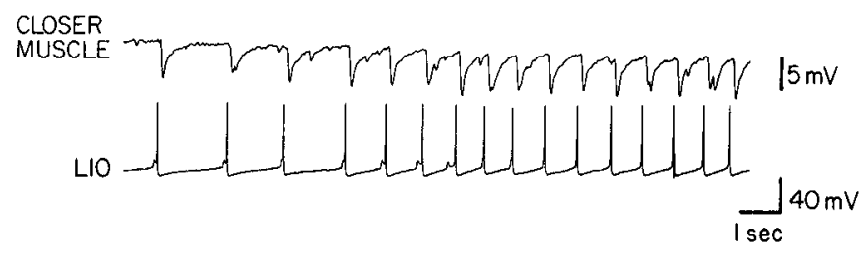

Figure 7. Intracellular recording of junction potentials elicited by $\mathrm{L} 10$ in muscle fibers of the renal pore (representative records from 7 preparations). $A$, Firing $\mathrm{L} 10$ by current injection elicited EJPs that followed the $\mathrm{L} 10$ action potentials $1: 1 . A 1$ and $A 2$ are from different muscle fibers in the same preparation. $B$, Firing L10 elicits IJPs in pore closer muscle that follow $\mathrm{L} 10$ action potentials $1: 1$. 

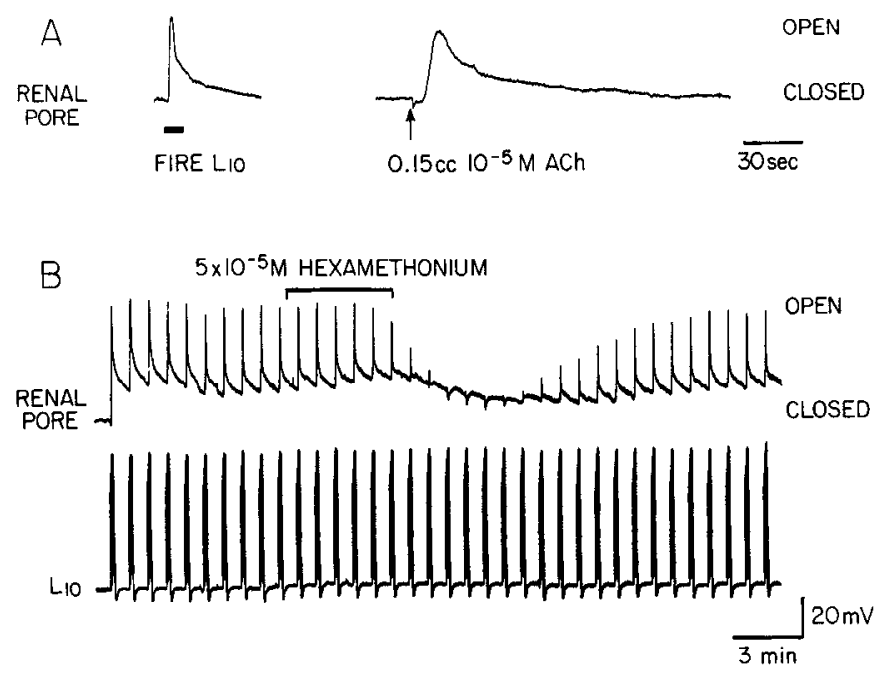

Figure 8. ACh, the transmitter used by $\mathrm{L} 10$, can mediate renal pore opening. L10 was fired in $10 \mathrm{sec}$ trains at $8 \mathrm{~Hz}$ in $A$ and $B$. $A$, Perfusion of the pore with a bolus of $\mathrm{ACh}$ opened the renal pore in a manner similar to firing L10 in 7 of 7 experiments. $B$, Perfusing the pore with hexamethonium, a selective blocker of the excitatory effects of $\mathrm{ACh}$ in Aplysia (McCaman and Ono, 1982), blocked the pore-opening action of $\mathrm{L} 10$ in 5 of 5 experiments. The delayed action of hexamethonium is due to delays in the perfusion system. The slight downward deflections in the renal pore trace during hexamethonium blockade reflect the fact that the pore opener muscle does not cause a purely radially symmetric opening effect; it also produces a rostral movement of the pore that appears to be mediated by the direct effect of L10 on pore muscle. As the caudal portion of the pore is pulled over the photocell, it sometimes registers a net decrease in light, which appears in the recording as a closing movement. When transmission to the pore is partially blocked by hexamethonium, this forward movement typically is affected less than are the radial opening movements. As a result, downward deflections such as those shown here are sometimes recorded.

between $\mathrm{L} 10$ spikes and individual twitches (Figs. $5 B, 6 B$ ) suggests that some of L10's effects may be filtered by the integrative properties of the RPO peripheral neuron.

\section{The RPO cell amplifies the effect of $L 10$ of renal pore opening}

In order to test whether the peripheral RPO cell might play a role in mediating L10's effects on pore opening, we recorded extracellularly from the pore region with a global macroelectrode $(n=6)$. Our recordings revealed a complex pattern of activity whenever L10 generated a high-frequency burst of action potentials. The results were similar whether the burst occurred spontaneously or was generated by injecting depolarizing current. The first 10-20 spikes in such a burst elicit 2 types of signals in the peripheral electrode: a brief, triphasic event $(I)$ follows the L10 soma action potential with a delay of about 30 msec (Fig. $9 A$ ). This signal is followed with a relatively constant latency by a slower biphasic event $(I I)$ (Fig. 9, $A, B$ ). Each L10 spike that occurs later in the train elicits these same 2 events $(I$ and $I I$ ). In addition, some of the later L10 spikcs also arc followed by 2 additional signals: a brief, small biphasic event (III, Fig. $9 A$ ), followed $1: 1$ by a larger, longer-lasting biphasic signal $(I V$, Fig. $9 A$ ). The latency between events $I$ and $I I I$ is highly variable, ranging between $20-140 \mathrm{msec}$ (Fig. 9B). In contrast, the latency between events $I I I$ and $I V$ is relatively constant, with most values in the range of $22-27 \mathrm{msec}$ (Fig. 9B).

To interpret this complex pattern of electrical activity, we propose the following hypothesis: I corresponds to the L10 ac-
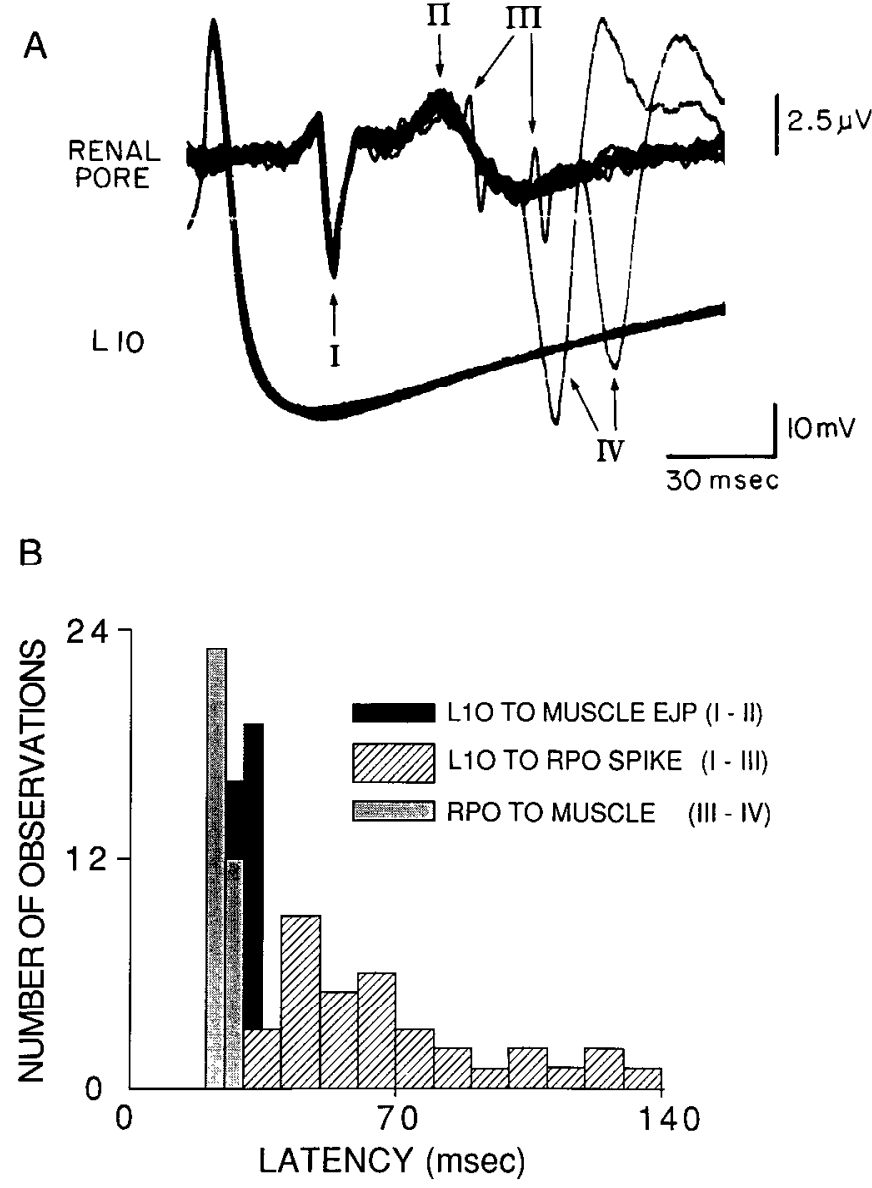

Figure 9. Global extracellular recording of neuromuscular activity in the renal pore region combined with intracellular recording from the soma of L10. $A$, With $\mathrm{L} 10$ fired at $4 \mathrm{~Hz}$ for $9 \mathrm{sec}$, the first several soma action potentials in the train were invariably associated with 2 electrical events in the periphery: $I$ corresponds to the arrival of L10's action potential in the periphery. $I I$ is caused by the EJPs directly elicited in pore opener muscle by L10. Later in the train, 2 additional types of signals occur intermittently. III signals the triggering of an action potential in the RPO cell. $I V$ is generated by a compound muscle potential elicited by the RPO cell. This record shows 10 overlapping traces from the middle of the train, at a time when facilitation of the L10-elicited junction potentials (II) is maximal (cf. Fig. 13B). B, Distribution of latencies between the electrical events recorded as in $A$ are consistent with the interpretation that the RPO spikes $(I I I)$ are triggered by $\mathrm{L} 10$ with a low safety factor for transmission, thus accounting for the wide range of latencies between $I$ and $I I I$. This low safety factor presumably reflects the fact that the L10-elicited EPSPs in RPO must facilitate and summate before reaching spike threshold. The much narrower range of latencies of $I$ and $I I$ (measured from the negative peak of $I$ to the positive peak of $I I$ ) is consistent with the hypothesis that this delay represents the L10 spike-to-muscle EJP delay. The equally narrow range of latencies for $I I I$ and $I V$ reflects the fact that $I I I$ and $I V$ measures either RPO spike to EJP latency, or RPO spike to muscle spike latency with a high safety margin for transmission.

tion potential arriving at the pore. $I I$ is caused by the compound EJP elicited by $L 10$ in the opener muscle fibers of the pore, and to a lesser extent by the EPSP that L10 elicits in RPO. The IJPs elicited by $\mathrm{L} 10$ in the closer muscle are unlikely to contribute much to this record, because the circular closer muscle fibers do not cross the high-resistance seal between the 2 extracellular recording electrodes. The brief duration and small amplitude of $I I I$ suggest that it is caused by an action potential in a single neuron, presumably RPO. The variable latency of $I I I$ and its 
Figure 10. Delayed recruitment of large compound muscle potentials during a spontaneously generated L10 burst. Simultaneous global extracellular recording from the renal pore and intracellular recording from the soma of $\mathrm{L} 10$. The burst in L10 generated L10 spikes and muscle EJPs in the extracellular record (at this speed they run together). Late in the burst, the RPO cell began to fire, generating 15 large compound muscle potentials (cf. $I V$ in Fig. 9A). At this recording speed, the RPO cell spikes cannot be distinguished.

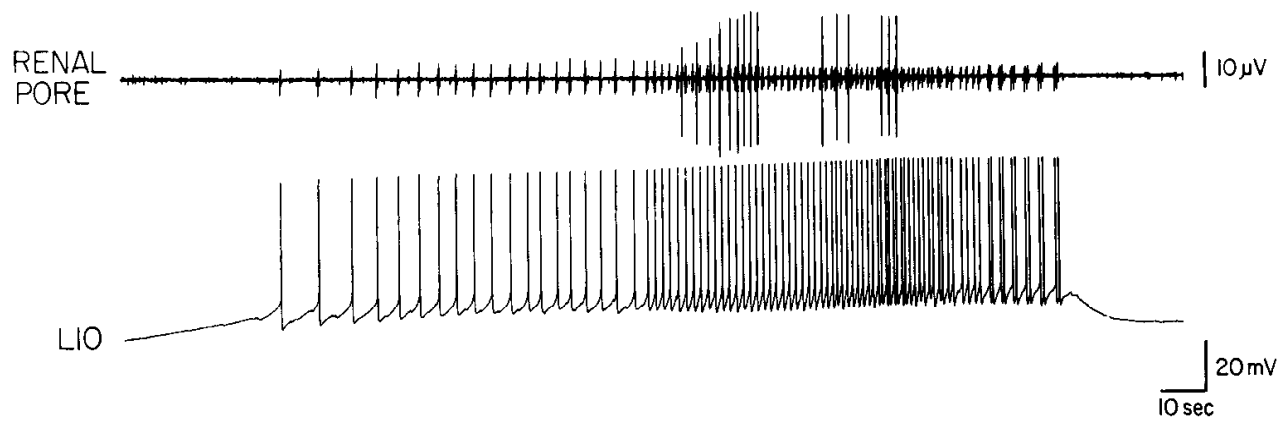

intermittent following of $I I$ could be explained if $I I I$ were elicited by facilitation and summation of the L10-elicited EPSPs in RPO. We propose that an action potential in RPO, as signaled by $I I I$, excites the opener muscle fiber with a high safety margin, generating $I V$. The waveform labeled $I V$ is presumed to be a population event in the muscle consisting of a compound EJP and, perhaps, a compound muscle action potential. We propose that these large electrical events ( $I V$ ) generate the discrete twitches recorded in the photocell records (Figs. 5B, 6B). Further support for the notion that $I V$ causes the discrete twitches comes from the fact that both events occur relatively late in a spontaneously generated L10 burst (cf. Figs. 5, $A, B$ and 10).

In 2 experiments, intracellular recording from RPO in a highly dissected preparation confirmed the above interpretation of the global extracellular record. We maximized the chances of impaling RPO in these experiments by using relatively large animals $(600$ and $1000 \mathrm{gm})$. We were unable to identify and record from L10 in the 2 large animals used in these experiments because of the exceptionally thick connective tissue capsule surrounding the ganglion. We could, however, record spontaneous trains of EPSPs in RPO (Fig. 11A). We conclude that these EPSPs are generated by L10, on the basis of 3 characteristic features of the bursts of EPSPs: the interburst frequency, the intraburst frequency, and the doublet and triplet EPSP patterns that occur late in each burst all were quite similar to the spontaneous L10 firing patterns observed in other preparations (Figs. 5, $A, B ; 10$; and figures 3 and 7 in Koester et al., 1974). The doublet EPSP patterns are particularly discriminating diagnostic features in this regard (cf. Figs. 10 and $11 C$ ).

The intracellular recordings from RPO provide 2 additional types of data that are consistent with our interpretation of the extracellularly recorded electrical events shown in Figure 9A: (1) Early in the train the intracellularly recorded EPSPs in RPO (Fig. $11, A, C$ ) and the extracellularly recorded putative EJPs (II in Fig. $9 A$ ) facilitated with approximately similar time courses (cf. Figs. 11, $A, C ; 13 B$ ). This facilitation has a time course similar to that observed for the EPSPs generated by L10 at its output synapses within the abdominal ganglion (Koester et al., 1974; Kretz et al., 1982). If one assumes that L10 exhibits the same kinetics of homosynaptic plasticity at each of its output
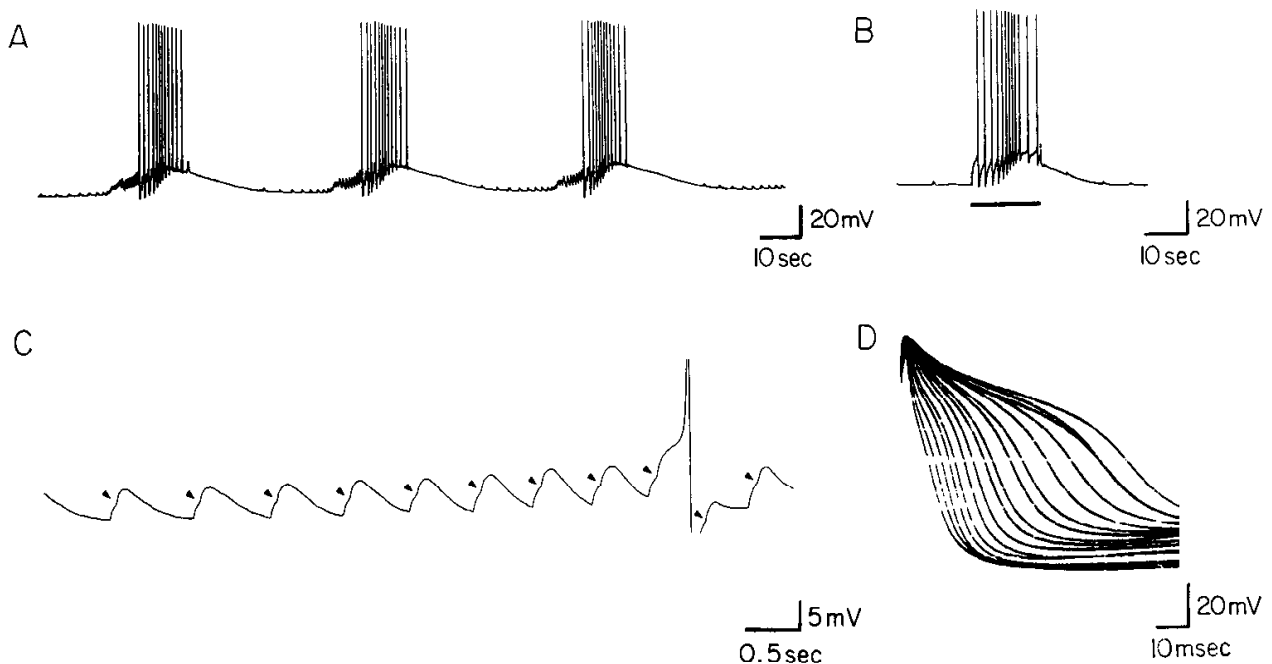

Figure 11. Intracellular recording from RPO. $A$, Three spontaneous bursts of EPSPs excited RPO at regular intervals. The temporal patterns of the spontaneous bursts are characteristic of the spontaneous bursting patterns of $L 10$. Late in each burst, synaptic facilitation and temporal summation were sufficient to allow intermittent driving of RPO by these L10-elicited EPSPs. B, The slow depolarization that underlies the synaptically driven burst in RPO can be mimicked by injection of depolarizing current. The horizontal bar marks the injection of a $0.25 \mathrm{nA}$ step of current into RPO. C'. During the middle phase of each burst in $A$, the EPSPs begin to arrive in the doublet pattern that is a unique characteristic of L10's spontaneous bursting pattern (cf. Figs. $5 B$ and 10, above, and fig. $3 A$ in Koester et al., 1974). Arrowheads mark inflections in the voltage trace caused by the second of each doublet pair of EPSPs. $D$. Progressive broadening of action potentials generated by RPO occurs during the burst. Sixteen overlapping traces were recorded from the cell shown in $A$ as it was being driven by a spontaneous burst in L10. During this burst, the mean firing frequency of RPO was $2 \mathrm{~Hz}$, and the maximum instantaneous frequency was $3.6 \mathrm{~Hz}$. 


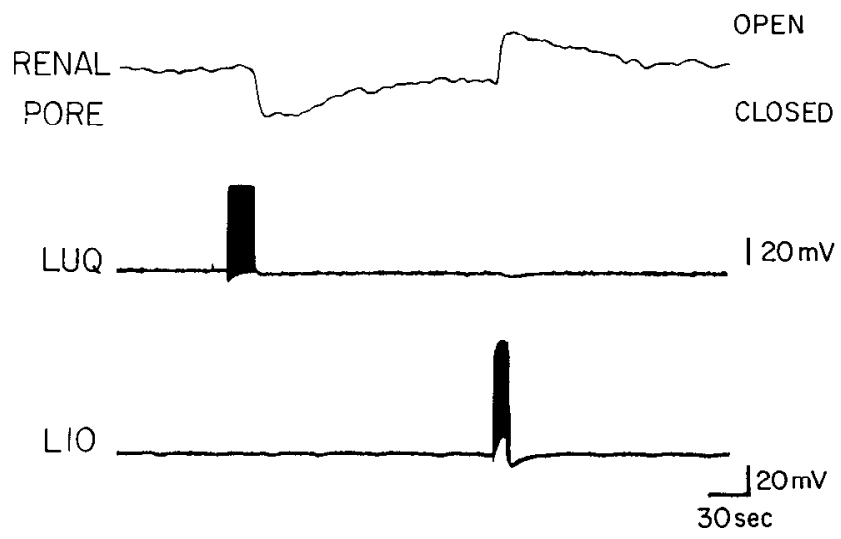

Figure 12. L10 and the LUQ cells have opposite motor effects on the renal pore. At the beginning of the trace, the pore was partially open. Firing the LUQ cell at $3 \mathrm{~Hz}$ caused complete closure of the pore; firing $\mathrm{L} 10$ at $9 \mathrm{~Hz}$ caused the pore to open fully.

terminals, these data would support the conclusion that $I I$ represents junction potentials generated by $\mathrm{L} 10$. (2) The facilitation and summation of the EPSPs in the intracellular record from RPO reach spike threshold relatively late in the EPSP train (Fig. $11 \mathrm{~A}$ ). This delayed recruitment of RPO spikes recorded intracellularly is consistent with the behavior of the 2 extracellular events that occur intermittently in the train, which we have attributed to spikes in RPO and to the compound muscle potentials that they generate in the opener muscle ( $I I I$ and $I V$ in Fig. 9A); these putative RPO and muscle potentials also occur only after L10 has fired 10-20 action potentials during a highfrequency burst (cf. Figs. 10, 11A).

The intracellular records from the RPO cell revealed 2 unusual electrical properties that may play an important role in the functioning of the cell. (1) A slow, low-amplitude depolarizing wave occurs in RPO during each L10-driven burst, accompanied by a significant reduction in the amplitude of the afterhyperpolarization that follows each action potential (Fig. $11 \mathrm{~A}$ ). These effects of synaptic excitation are apparently caused at least in part by voltage-dependent mechanisms endogenous to RPO, as they also can be elicited by injection of a depolarizing current pulse from the recording electrode (Fig. 11B). (2) When a spontaneous burst in $\mathrm{L} 10$ begins to trigger action potentials intermittently in RPO (Fig. 11A), the later RPO spikes in the train exhibit a 5 - to 10 -fold broadening (Fig. 11D). This broadening of the action potentials in the RPO soma may have a significant effect on the efficacy of transmitter release by RPO, if it is reflected in the activity of the cell's presynaptic terminals (see Coates and Bulloch, 1985).

\section{The LUQ cells mediate renal pore closing}

In 17 out of 20 preparations, at least 1 and as many as 3 of the LUQ cells were found to have motor effects on the renal pore that are antagonistic to that of L10. Because in some of these preparations only 1 or 2 of the 5 LUQ cells could be impaled, it is likely that in every preparation at least 1 LUQ cell has such effects. Firing one of the antagonistic LUQ cells by current injection caused the renal pore to close following a several second delay (Fig. 12). In addition to causing pore closure, activity in an LUQ cell blocks the ability of L10 to trigger opening of the pore (Fig. 13A). The actions of the LUQ cells appear to result from direct effects of these cells in the periphery, because morphological (Fig. 4) and electrical data show that the LUQ cells
A
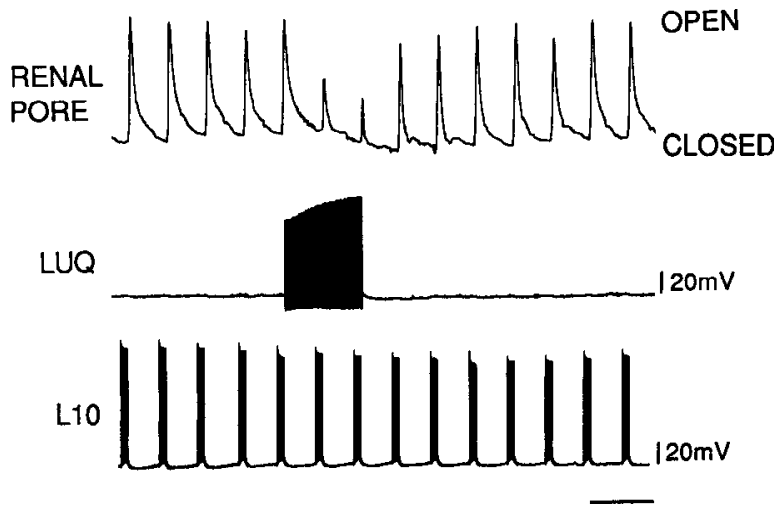

$1 \mathrm{~min}$

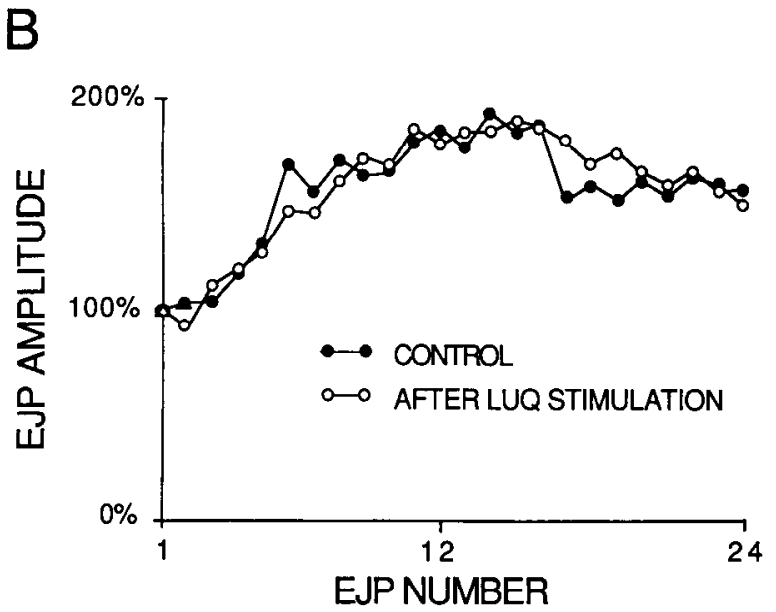

Figure 13. The LUQ cells antagonize the actions of L10 on the renal pore, with no effect on the L10-to-muscle EJP. $A$, Firing L10 at $5 \mathrm{~Hz}$ by injecting $5 \mathrm{sec}$ trains of brief depolarizing current pulses causes transient openings of the renal pore. Firing an LUQ cell for $60 \mathrm{sec}$ at $1 \mathrm{~Hz}$. antagonizes the opening action of $\mathrm{L} 10$ and partially closes the pore. $B$, A stimulation protocol similar to that in $A$ was used while recording extracellularly from the renal pore. The amplitude of the L10-elicited junction potential (event $I I$ in Fig. $9 A$ ) facilitated during the $\mathrm{L} 10$ spike train. A train of spikes fired in an LUQ cell just before the train in L10 had no effect on the L10-elicited junction potential (II) but completely blocked the RPO action potentials $(I I I)$ and the muscle potentials $(I V)$ that they trigger, as in Figure 14 (below). Each point represents the average of 3 control or 4 experimental (following LUQ stimulation) runs, normalized to the first junction potential in each train. L10 was fired at $3 \mathrm{~Hz}$, and the LUQ cell was fired at $3 \mathrm{~Hz}$ for $25 \mathrm{sec}$ immediately before each experimental train.

send axons to the pore, and their inhibitory motor effects persist with the ganglion bathed either in $\mathrm{Ca}^{2+}$-free, $\mathrm{Co}^{2+}$ solution or in high divalent cation solution to block polysynaptic pathways in the ganglion (data not shown).

At least part of the inhibition of renal porc opcning by the LUQ cells is mediated at the level of the RPO cell. Figure 14 shows that firing a single LUQ cell for 30-60 sec blocks the muscle potentials $(I V)$ that are elicited by an L10 spike train in the global extracellular recording. Playing back such a record at high chart speed reveals that the RPO spikes $(I I I)$ also are blocked by the train of LUQ spikes ( $n=4$, data not shown). This inhibitory action indicates that firing the LUQ cell depresses helerosynaptically the excitatory L10 to RPO connection. In con- 

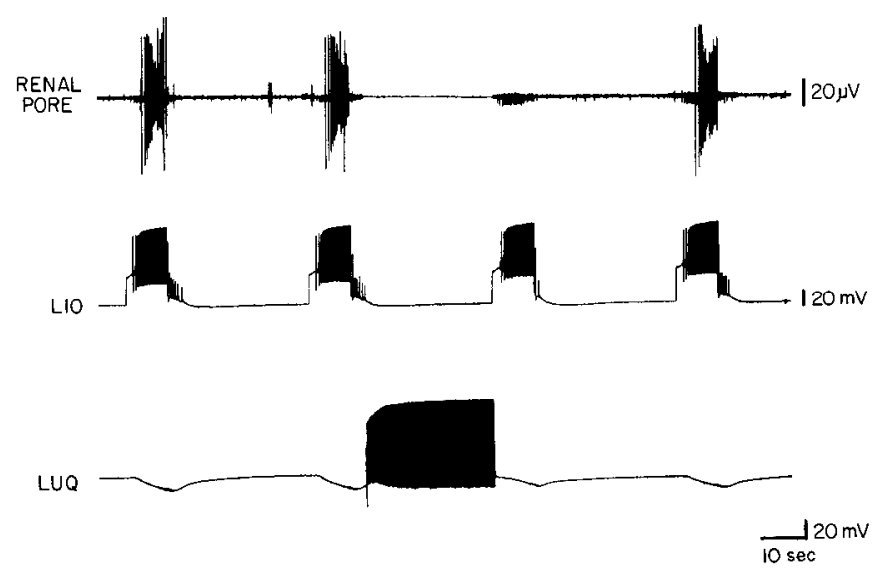

Figure 14. The LUQ cells heterosynaptically depress the L10 to RPO synapse. Firing $\mathrm{L} 10$ at a mean rate of $5 \mathrm{~Hz}$ for 8 sec triggers a train of RPO action potentials (III), which drive a series of compound muscle potentials $(I V)$. Firing an LUQ cell at $3 \mathrm{~Hz}$ for $30 \mathrm{sec}$ blocks both RPO spikes and the muscle potentials. At this recording speed, only the muscle potentials (IV) can be discerned. Playing the records out at high chart paper speed showed that both the RPO spikes $(I I I)$ and the muscle potentials $(I V)$ were eliminated in the response that followed the LUQ burst. The abdominal ganglion was bathed in high divalent cation solution to reduce polysynaptic transmission.

The input to the extracellular amplifier was grounded during the time that the LUQ cell was fired, in order to blank out the large stimulus artifacts that are picked up by capacitive coupling from the brief current pulses injected into the LUQ-stimulating electrode. Because L10 was fired by injecting a long-lasting DC current pulse, capacitive artifacts arising from the L 10 electrode were negligible. The LUQ cell had a slight inhibitory effect on $\mathrm{L} 10$, revealed primarily by the decreased afterdepolarization following the third L10 train (see Fig. 15, below). However, the temporal firing pattern within the L10 train was not affected by this weak inhibition.

trast, the directly mediated L10 to muscle EJP $(I I)$ is unaffected by LUQ cell activity (Fig. 13B), consistent with the observation that the slow, graded contractions produced by these EJPs are unaffected by firing LUQ cells (data not shown). The experiments illustrated in Figures $13 B$ and 14 were performed with the abdominal ganglion bathed in high divalent ASW to reduce polysynaptic transmission.

The antagonistic actions of L10 and the LUQ cells in the periphery are complemented by mutually inhibitory connections within the abdominal ganglion. It had been reported previously that L10 strongly inhibits the LUQ cells (Kandel et al., 1967) (see Fig. 14). These connections undoubtably serve to coordinate the actions of these 2 cell types at the periphery. We have found, in $20 \%$ of ganglia we recorded from, that at least one LUQ cell also could exert a weak inhibitory action on L10, when fired at high frequencies $(3-10 \mathrm{~Hz}$ for several sec) (Fig. 15). The minimum effective LUQ firing frequencies are about 6 times those that occur spontaneously in the semi-intact preparation, raising a question about the physiological relevance of the LUQ to L10 synapses. Wc have not cxamined these connections in high divalent cation ASW to test for monosynapticity, but it has been reported recently that when an LUQ cell and L10 are isolated in cell culture, the LUQ cell can inhibit L10 directly (Kleinfeld et al., 1988).

\section{Discussion}

Figure 16 summarizes our knowledge of the connections made by L10, the LUQ cells, and RPO to each other and to the muscle

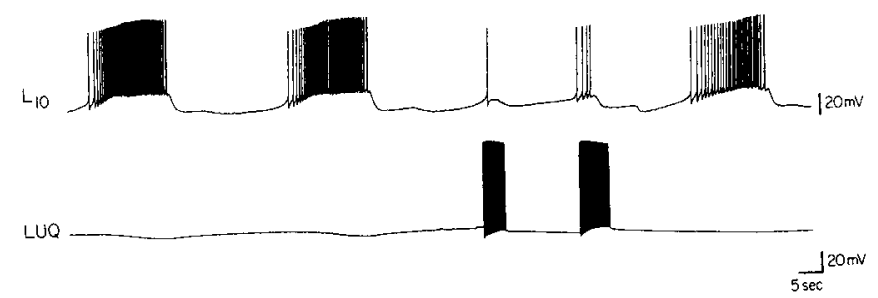

Figure 15. LUQ cells weakly inhibit $L 10$ in some preparations. In this experiment, firing a single LUQ cell at $10 \mathrm{~Hz}$ for several seconds blocked the endogenously generated bursts in L10.

groups of the renal pore. The data are not sufficient to determine whether the heterosynaptic inhibition of the L10 to RPO connection by LUQ activity is pre- or postsynaptically mediated, or both. Nor do we have evidence that bears directly on the question of whether the LUQ cells also directly innervate the opener or closer muscle of the pore. We believe that such connections to closer muscle are likely, however, because firing a single LUQ cell at high frequency can cause active contraction of the pore, even when transmission in the ganglion is blocked. From the spontaneous EJPs and IJPs recorded in pore muscle (Fig. 7), it is clear that L10 is not the only cell that directly innervates the muscle of the renal pore. Because these spontaneous PSPs have the same polarity as those from L10, they are unlikely to be generated by the LUQ cells, which have motor effects on the renal pore opposite to those of L10. Thus, we believe that cells other than L10 or the LUQ cells also innervate the pore muscle.

\section{L10 has a central role in controlling renal function}

The anatomical and physiological data described here suggest that the primary role of $\mathrm{L} 10$ may be the control of renal function: (1) By increasing heart rate via excitation of $\mathrm{RB}_{\mathrm{HE}}$ (Koester et al., 1974), L10 may increase renal filtration across the wall of the crista aortae. (2) By its direct and indirect actions on the renal porc (Fig. 16), L10 may increase the outflow of urine. (3) L10 also branches extensively to other parts of the kidney (Fig. $4 B$ ). These branches may serve to mediate effects on the contraction of kidney muscle, on secretory and reabsorptive activity, and on ciliary activity within the renal-pericardial pore. (4) L10 excites not only $\mathrm{RH}_{\mathrm{HE}}$, but all of the other cells in the $\mathrm{RB}$ cluster (Kandel et al., 1967). The RB cells have been shown previously to be serotonergic (Eisenstadt et al., 1973; Weinreich et al., 1973; Kistler et al., 1985). Several members of the RB cluster send axons out the peripheral nerves that innervate the kidney and the crista aortae (Frazier et al., 1967; Winlow and Kandel, 1976). Thus, some of the serotonergic innervation of these structures may come from the RB cells, and L10 may exert additional indirect effects on renal function by exciting these cells. More direct physiological measurements of renal function will be required to test our hypothesis that L10 plays a central role in integrating the overall neuronal control of renal function.

L10 clearly exerts powerful effects on the renal pore at its normal spontaneous firing rate recorded in the semi-intact preparation. Chronic recording from L10 in the freely moving, intact animal will be required to determine whether these firing rates fall within the normal physiological range. It is interesting in this regard that pulsatile renal excretion of the type apparently produced by L10 in Aplysia has been observed in 2 other gastropods - the freshwater prosobranch Viviparus viviparus (Little, 


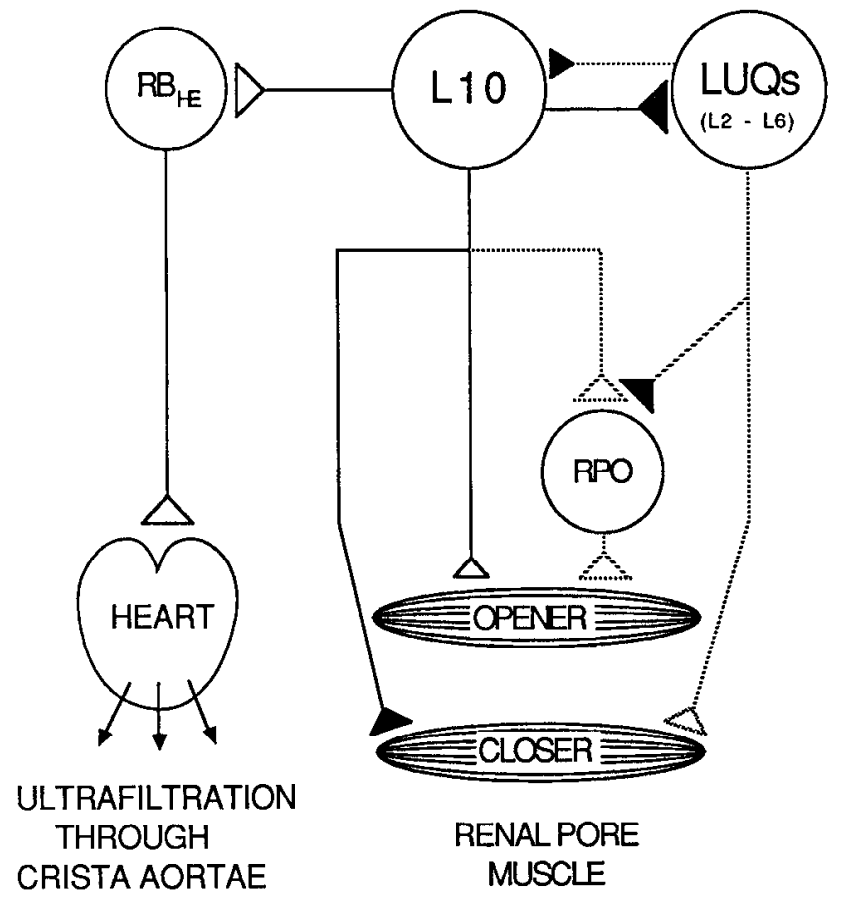

Figure 16. Summary diagram showing the connections made by L10, $\mathrm{RPO}$, and the LUQ cells that affect renal functioning. Black, inhibition; white, excitation. It is not known whether the heterosynaptic depression of the L10 to RPO connection by the LUQ cells is pre- or postsynaptic, or both. The LUQ to L10 connections are weak when present and are found in only $20 \%$ of preparations. Solid lines show connections that have been demonstrated by pairwise intracellular recording to be monosynaptic. The connections from L10 to RPO and from RPO to the muscle have been inferred on the basis of indirect evidence. See Koester and Kandel (1977) and Segal and Koester (1982) for a more complete description of the connections made by L 10 within the abdominal ganglion.

1965 ) and the freshwater pulmonate Lymnea stagnalis (de With and van der Schors, 1984).

\section{The LUQ cells antagonize the peripheral actions of $L 10$}

Our results indicate that the LUQ cells also play an important role in the control of kidney function. Some, and perhaps all, of the LUQ cells branch extensively within the kidney. Their one physiological effect in the kidney that we have identified is to oppose the effects of L10 on the renal pore. Firing an LUQ cell can cause active closure of the renal pore and can antagonize the pore opening triggered by L10. This pcriphcral antagonism is coordinated by a strong central inhibition of the LUQ cells by L10 (Kandel et al., 1967) and a weaker, highly variable reciprocal inhibitory connection. LUQ cells can be distinguished as unique individuals using a number of morphological, biochemical, physiological, and pharmacological criteria (Frazier et al., 1967; Winlow and Kandel, 1976; Taussig et al., 1985; Evans et al., 1987; Pearson and Lloyd, 1989). We have not yet systematically surveyed the entire population of LUQ cells to determine specifically which cells act on the renal pore and how they differ in their peripheral fields of innervation. The minimal effective firing rate for an individual LUQ cell to completely block L10's action on renal pore activity was about $1 \mathrm{~Hz}$, roughly twice the maximum mean spontaneous firing rate recorded from LUQ cells in our reduced preparations. However, given the fact that as many as 3 LUQ cells can converge on the pore in an individual animal, the net effect of the entire population of cells firing at $0.5 \mathrm{~Hz}$ may be sufficient to modulate renal pore opening. Moreover, some of the LUQ cells may innervate the pore via their axon branches in the genital and branchial nerves. We cut these nerves in all of our experiments, and thus may have underestimated the effect of the LUQ cells on renal closure. Finally, the natural bursting patterns exhibited by these cells (Frazier et al., 1967) may be more efficient at releasing transmitter than the steady patterns used in our experiments, and there may be heterosynaptic facilitation in vivo of the LUQ connections in the periphery by other, as yet unidentified, neurons.

\section{The RPO peripheral motoneuron}

Peripheral sensory and motoneurons are widely distributed in molluscs (reviewed by Janse, 1974; Vehovszky and Elekes, 1985). In Aplysia, both sensory and motor peripheral neurons have been described in various regions of the periphery, including the mantle organs (Peretz and Moller, 1974; Bailey et al., 1979), the reproductive system (Salimova et al., 1987), the sensory epithelium of the rhinophores and anterior tentacles (Emery and Audesirk, 1978), and the digestive system (Lloyd et al., 1988). With the exception of a single neurosecretory cell found on the siphon nerve (Bailey et al., 1979), the peripheral neurons in molluscs cannot be identified as unique individuals. The RPO neuron found embedded in the right rostral wall of the renal pore is not only an identified cell, but also receives excitatory synaptic input from cell $\mathrm{L} 10$, and the effectiveness of this input is modulated by the LUQ cells. Thus, RPO provides an excellent vantage point from which to study the interaction between the central and peripheral nervous systems at the cellular level.

It is not clear what, if any, functional advantage results from having a peripheral motoneuron interposed between L10 and the opener muscle of the renal pore. One possibility is suggested by the widespread branching patterns of L10 and the LUQ cells in the periphery. Assuming that these branches lead to output synapses, and given the widespread set of connections made by L10 within the abdominal ganglion (Segal and Koester, 1982), it is probable that both L10 and the LUQ cells exert control over renal physiology at a number of sites. It is also likely that the most adaptive set of responses for this combination of sites may vary under different physiological or behavioral conditions. Thus, it may be useful to think of L10 more as an interneuron with important integrative functions, than as simply a final common output pathway to the effector organs. In this context, RPO may be thought of as the dominant final common motor element that integrates the premotor output targeted to the opener musclc of the renal porc. Its presence provides the control system for renal function with one additional degree of freedom.

\section{References}

Alevizos, A., K. R. Weiss, and J. Koester (1987) Myomodulin: A possible cotransmitter of the cholinergic neuron L10 of Aplysia. Soc. Neurosci. Abstr. 13: 1072.

Alevizos, A., C. H. Bailey, M. Chen, and J. Koester (1989) Innervation of vascular and cardiac muscle of Aplysia by multimodal motoneuron L7. J. Neurophysiol. 61: 1053-1063.

Andrews, E. B. (1988) Excretory systems of molluscs. In The Mollusca, Vol. 11, A. S. M. Saleuddin and K. M. Wilbur, eds., pp. 381-448, Academic, New York.

Bailey, C. H., V. F. Castellucci, J. Koester, and E. R. Kandel (1979) Cellular studies of peripheral neurons in siphon skin of Aplysia californica. J. Neurophysiol. 42: 530-557.

Brown, R. O., D. Gusman, A. I. Basbaum, and E. Mayeri (1985) Iden- 
tification of Aplysia neurons containing immunoreactive FMRFamide. Neuropeptides 6: 517-526.

Coates, C. J., and G. M. Bulloch (1985) Synaptic plasticity in the molluscan peripheral nervous system: Physiology and role for peptides. J. Neurosci. 5: 2677-2684.

Cropper, E. C., R. Tenenbaum, M. A. Kolks, I. Kupfermann, and K. R. Weiss (1987) Myomodulin: A bioactive neuropeptide present in an identified cholinergic buccal motor neuron of Aplysia. Proc. Natl. Acad. Sci. USA 84: 5483-5486.

de With, N. D., and R. C. van der Schors (1984) Urine composition and kidney function in the pulmonate freshwater snail Lymnaea stagnalis. Comp. Biochem. Physiol. 79A: 99-103.

DiVirgilio, F., T. H. Steinberg, J. A. Swanson, and S. C. Silverstein (1988) Fura-2 secretion and sequestration in macrophages. J. Immunol. 140: 915-920.

Eales, N. B. (1921) Aplysia. Liverpool Marine Biology Committee, Proc. Trans. Liverpool Biol. Soc. L.M.B.C. Mem. Vol. 35, 24: 183266.

Eisenstadt, M., J. E. Goldman, E. R. Kandel, H. Koike, J. Koester, and J. H. Schwartz (1973) Intrasomatic injection of radioactive precursors for studying transmitter synthesis in identified neurons of Aplysia californica. Proc. Natl. Acad. Sci. USA 70: 3371-3375.

Fmery, D. G., and T. F. Audesirk (1978) Sensory cells in Aplysia J. Neurobiol. 9: 173-179.

Evans, M. L., M. J. Kadan, P. R. Hartig, and D. O. Carpenter (1987) Correlation of a specific serotonin-induced membrane current with 125I-LSD binding sites on identified Aplysia neurons. Soc. Neurosci. Abstr. 13: 1072.

Frazier, W. T., E. R. Kandel, I. Kupfermann, R. Waziri, and R. E. Coggeshall (1967) Morphological and functional properties of identified neurons in the abdominal ganglion of Aplysia californica. J. Neurophysiol. 30: 1288-1351.

Furgal, S. M., and P. H. Brownell (1987) Ganglionic circulation and its effects on neurons controlling cardiovascular functions in Aplysia californica. J. Exp. Zool. 244: 347-363.

Gillette, R., and B. Pomeranz (1973) A study of neuron morphology in Aplysia californica using procion yellow dye. Comp. Biochem. Physiol. 44A: 1257-1259.

Hawkins, R. D. (1986) Localization of potential serotonergic facilitator neurons by glyoxylic acid histofluorescence and retrograde labeling in Aplysia. Soc. Neurosci. Abstr. 12: 1339.

Janse, C. (1974) A neurophysiological study of the peripheral tactile system of the pond snail Lymnaea stagnalis (L.). Neth. J. Zool. 24: 93-161.

Kandel, E. R. (1976) The Cellular Basis of Behavior, Freeman, San Francisco.

Kandel, E. R. (1979) Behavioral Biology of Aplysia, Freeman, San Francisco.

Kandel, E. R., W. T. Frazier, R. Waziri, and R. E. Coggeshall (1967) Direct and common connections among identified neurons in Aplysia. J. Neurophysiol. 30: 1352-1376.

Kistler, H. B., R. D. Hawkins, J. Koester, H. W. M. Steinbusch, E. R. Kandel, and J. H. Schwartz (1985) Distribution of serotonin-immunoreactive cell-bodies and processes in the abdominal ganglion of mature Aplysia. J. Neurosci. 5: 72-80.

Kleinfeld, D., G. F. Raccuia, and H. J. Chiel (1988) Circuits with bistable outputs constructed from identified neurons. Soc. Neurosci. Abstr. 14: 841.

Koester, J. (1988) Modulation of Aplysia renal pore activity by L10, the LUQ cells, and an identified peripheral motoneuron. Soc. Neurosci. Abstr. 14: 1000 .

Koester, J., and E. R. Kandel (1977) Further identification of neurons in the abdominal ganglion of Aplysia using behavioral criteria. Brain Res. 121: 1-20.

Koester, J., E. Mayeri, G. Liebeswar, and E. R. Kandel (1974) Neural control of circulation in Aplysia. II. Interneurons. J. Neurophysiol. 37: 476-496.

Koester, J., M. Chen, and C. H. Bailey (1987) Modulation of renal pore activity by L10 and the LUQ cells of Aplysia. Soc. Neurosci. Abstr., 13: 1515.

Kramer, R. H., and R. S. Zucker (1985) Calcium-induced inactivation of calcium current causes the inter-burst hyperpolarization of Aplysia bursting neurones. J. Physiol. (Lond.) 362: 131-160.

Kretz, R., E. Shapiro, and E. R. Kandel (1982) Post-tetanic potentiation at an identified synapse in Aplysia is correlated with a $\mathrm{Ca}^{++}$. activated $\mathrm{K}^{+}$current in the presynaptic neuron: Evidence for $\mathrm{Ca}^{++}$ accumulation. Proc. Natl. Acad. Sci. USA 79: 5430-5434.

Lehman, H. K., D. A. Price, and M. J. Greenberg (1984) The FMRFamide-like neuropeptide of Aplysia is FMRFamide. Biol. Bull. 167: 460-466.

Little, C. (1965) The formation of urine by the prosobranch gastropod mollusc Viviparus viviparus linn. J. Exp. Biol. 43: 39-54.

Lloyd, P. E., I. Kupfermann, and K. R. Weiss (1988) Central peptidergic neurons regulate gut motility in Aplysia. J. Neurophysiol. 59: 1613-1626.

Longley, R. D., and A. J. Longley (1986) Serotonin immunoreactivity of neurons in the gastropod Aplysia californica. J. Neurobiol. 17:339358.

Mayeri, E., J. Koester, I. Kupfermann, G. Liebeswar, and E. R. Kandel (1974) Neural control of circulation in Aplysia. I. Motoneurons. J. Neurophysiol. 37: 458-475.

Mayeri, E., P. Brownell, W. D. Branton, and S. B. Simon (1979a) Multiple, prolonged actions of neuroendocrine bag cells on neurons in Aplysia. I. Effects on bursting pacemaker neurons. J. Neurophysiol. 42: 1165-1184.

Mayeri, E., P. Brownell, and W. D. Branton (1979b) Multiple, prolonged actions of neuroendocrine bag cells on neurons in Aplysia. II. Fffects on heating pacemaker and silent neurons. J. Neurophysiol. 42 . 1185-1197.

McCaman, R. E., and J. K. Ono (1982) Aplysia cholinergic synapses: A model for central cholincrgic function. In Progress in Cholinergic Biology, Model Cholinergic Synapses, I. Hanin and A. M. Goldberg, eds., pp. 23-43, Raven, New York.

Ono, J., and R. E. McCaman (1984) Immunocytochemical localization and direct assays of serotonin-containing neurons in Aplysia. Neuroscience 11: 549-560

Pearson, W. L., and P. E. Lloyd (1989) Immunocytological localization of pedal peptide in the central nervous system and periphery of $A p l y$ sia. J. Neurosci. 9: 318-325.

Peretz, B., and R. Moller (1974) Control of habituation of the withdrawal reflex by the gill ganglion in Aplysia. J. Neurobiol. 5: 191212.

Pinsker, H. M. (1977) Aplysia bursting neurons as endogenous oscillators. II. Synchronization and entrainment by pulsed inhibitory synaptic input. J. Neurophysiol. 40: 544-556.

Rao, G., C. A. Barnes, and B. L. McNaughton (1986) Intracellular fluorescent staining with carboxyfluorescein: $A$ rapid and reliable method for quantifying dye-coupling in mammalian central nervous system. J. Neurosci. Methods 16: 251-263.

Rittenhouse, A. R., and C. H. Price (1986) Axons and target tissues of Aplysia neurons R3-14 and their status as multifunctional, multimessenger neurons. J. Neurosci. 6: 2071-2084.

Salimova, N, B., D. A. Sakharov, I. Milosevic, and L. Rakic (1987) Catecholamine-containing neurons in the peripheral nervous system of Aplysia. Acta Biol. Hung. 38: 203-212.

Segal, M. M., and J. Koester (1982) Convergent cholinergic neurons produce similar postsynaptic actions in Aplysia: Implications for neural organization. J. Neurophysiol. 47: 742-759.

Shyamala, M., J. M. Fisher, and R. H. Scheller (1986) A neuropeptide precursor expressed in Aplysia neuron L5. DNA 5: 203-220.

Taussig, R., R. R. Kaldany, J. B. Rothbard, G. Schoolnik, and R. H. Scheller (1985) Expression of the L1l neuropeptide gene in the Aplysia central nervous system. J. Comp. Neurol. 238: 53-64.

Vehovszky, A., and K. Elekes (1985) Electrophysiological characteristics of peripheral neurons and their synaptic connections in the intestinal nerve of Helix pomatia L. Comp. Biochem. Physiol. $82 \mathrm{~A}$ : 345-353.

Verhaert, P., C. J. P. Grimmelikhuijzen, and A. De Loof (1985) Distinct localization of FMRFamide- and bovine pancreatic polypeptidelike material in the brain. Retrocerebral complex and suboesophageal ganglion of the cockroach Periplaneta americana L. Brain Res. 348: 331-338.

Weinreich, D., M. W. McCaman, R. E. McCaman, and J. E. Vaughn (1973) Chemical enzymatic and ultrastructural characterization of 5-hydroxytryptamine-containing neurons from the ganglia of Aplysia californica and Tritonia diomedia. J. Neurochem. 20:969-976.

Winlow, W., and E. R. Kandel (1976) The morphology of identified neurons in the abdominal ganglion of Aplysia californica. Brain Res. 112: 221-249. 